\title{
Yield Prediction by Integrating NDVI and N-Tester Data with Yield Monitor Data
}

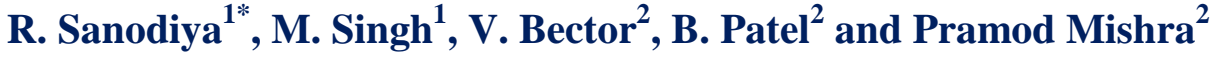 \\ ${ }^{1}$ Department of Farm Machinery and Power Engineering, PAU, Ludhiana, 141004, Punjab, India \\ ${ }^{2}$ IARI, New Delhi, India \\ *Corresponding author
}

A B S T R A C T

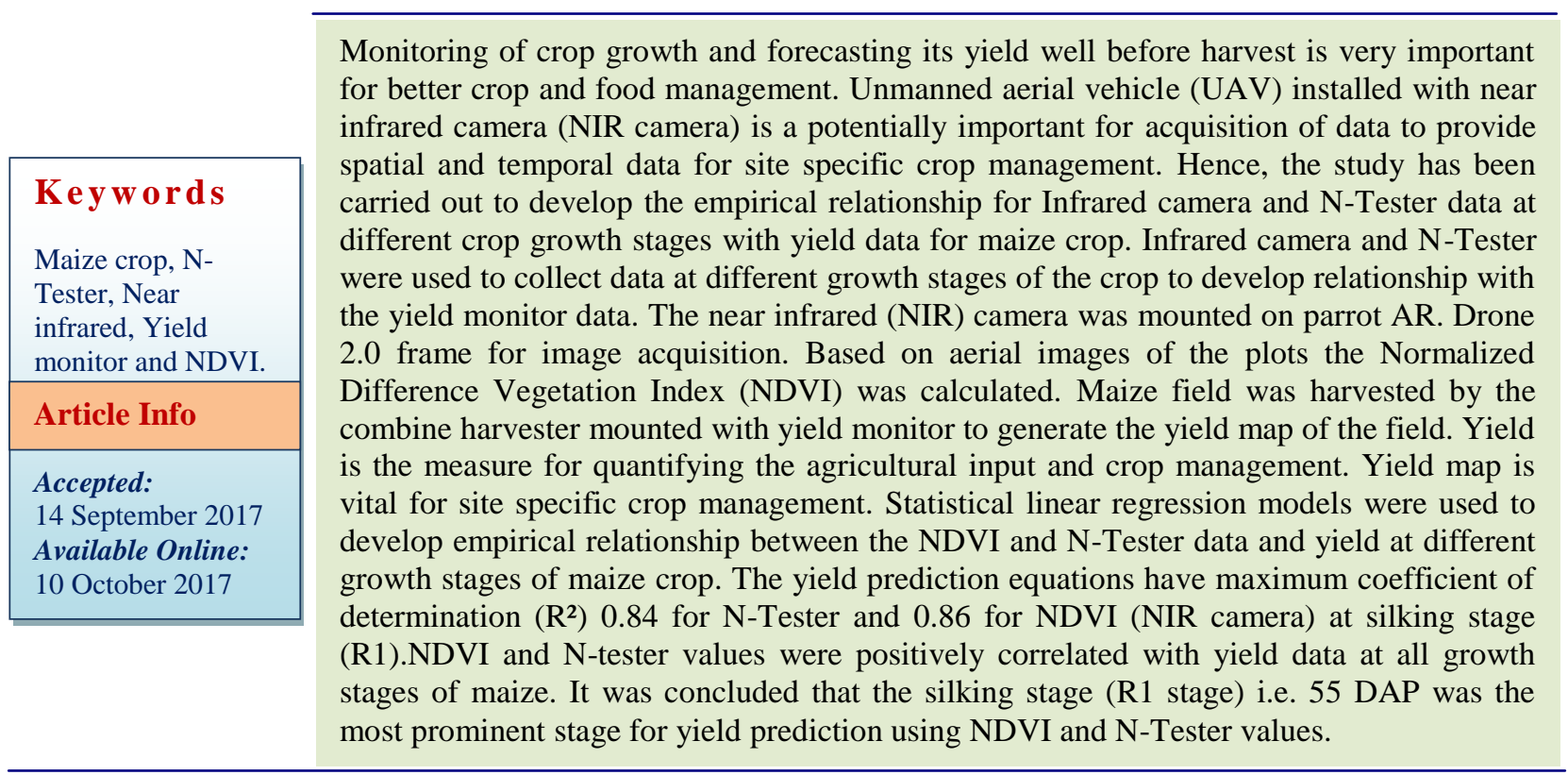

\section{Introduction}

Precision farming is one of the technology which helps to increase productivity and production by availing real time precise monitoring. There are three basic steps in precision farming viz. assessing variability, managing variability and evaluation. So, there is a need of a device which gives an accurate assessment of yield variability and this need can be fulfilled by the use of yield monitor (Singh et al., 2012). Yield maps provide feedback for determining the effects of managed inputs such as fertilizer, seed and pesticides and cultural practices such as tillage irrigation and drainage. Monitoring of crop yield is the most important operation to any farmer (Sharma et al., 2012).

High spatial resolution air and satellite borne imagery can aid in the development of information basis to rapidly map spatial variations in crop productivity, assisting managers to find the causes of such variability 
so that better management strategies can be implemented. Methods for large-scale mapping of crop variability are needed for precision farming applications (Tomer et al., 2005). So it was hypothesized that aerialinfrared photographs can predict corn yield and $\mathrm{N}$ uptake variability. The vegetation indices derived from aerial images as biomass and yield prediction tools (Villegas and Fritschi, 2013; Jensen et al., 2007; Shanahan et al., 2001; Reyniers et al., 2006). Yang et al., (2004) and Halloran (2004) evaluated the relationships between yield monitor data and airborne multi-date multispectral digital imagery. These results demonstrated that airborne digital imagery can be a very useful tool for determining yield patterns before harvest for precision agriculture.

Yield forecasting is important for determining import-export policies, government aid for farmers, and allocation of subsidies for regional agricultural programs (Zand and Matinfar 2012). It is extremely useful for farmers, crop and food management. An alternative method to predict yield variability is to use remote sensing. Many studies have been conducted to correlate remotely sensed data in the form of vegetation indices with the yield of various crops (Yang and Anderson 1996, Taylor et al., 1997, Zhang et al., 1998, Diker et al., 2001, Diker and Bausch 2003).

Remote sensing images are capable of identifying crop health, as well as predicting its yield. Normalized Difference Vegetation Index (NDVI) calculated from remotely sensed data have been widely used to monitor crop growth and to predict crop yield (Bala and Islam 2009). There is strong correlation between $\mathrm{N}$-Tester reading with grain yield and leaf $\mathrm{N}$ concentration (Schepers and Francis 1998, Schepers et al., 1992, Anand and Byju 2008, Rostami et al., 2008). The infrared camera and $\mathrm{N}$-Tester reading indicates the plant nutrition and nitrogen status of the plant.
This study describes research undertaken on applications of infrared images captured by infrared camera installed on drone for precision crop management and crop yield prediction. The relationship between remotely sensed data at different crop growth stages and yield data to predict crop yield well before harvesting will help in better crop management and planning of the next season's inputs but there is no effective relationship available between different crop growth stages and yield data. Hence, the research has been carried out to develop the empirical relationship between remotely sensed data at different crop growth stages and yield data for maize crop.

\section{Materials and Methods}

\section{Experimental treatments}

The field location was at $30^{\circ} 54^{\prime} 36.544^{\prime \prime} \mathrm{N}$ latitude and 75'49'03.974" E longitude and experiment conducted during kharif season, 2015 at the experimental farm of Department of Farm Machinery and Power Engineering, Punjab Agricultural University, Ludhiana, Punjab, India. Soil of field is sandy loam in texture, non-saline, non-calcareous and neutral in reaction.

Maize crop (PMH-1 cultivars) was grown and managed as per agronomic practices recommended by the university. Harvesting of maize crop was done by using axial flow type combine harvester fitted with optical type yield monitor.

\section{Field layout and data collection}

Design of experiment was selected completely randomized design (CRD) having 36 plots of size $15 \times 10\left(150 \mathrm{~m}^{2}\right)$ each were sown at row to row spacing of $67.5 \mathrm{~cm}$ and plant to plant spacing of $20.0 \mathrm{~cm}$. The

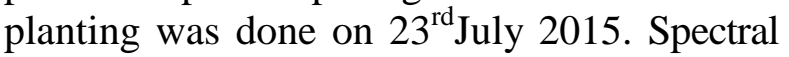
properties of maize plants were captured using 
N-Tester and near infrared (NIR) camera. Spectral properties were measured at three growth stages. Starting from grand growth stage (35 DAP) to dough stage (78 DAP) (Table 1). First fully exposed leaf from top of the plant was used as an index leaf to measure the spectral properties by N-Tester.

\section{Nitrogen-Tester (N-Tester)}

Nitrogen-Tester (Make: Yara, Germany) is a device for detecting the chlorophyll content of plant leaves based on the amount of light that is absorbed by the chlorophyll pigments. Typically the measurement is to be conducted at the youngest fully developed leaf of a plant. The N-Tester value (usually a value between 300 and 700) is closely related to the chlorophyll content and (indirectly) also to the $\mathrm{N}$ content of the plant with higher reading indicating higher contents. $\mathrm{N}$-Tester measures the light transmitted by the plant leaf at two different wavelengths i.e. $650 \mathrm{~nm}$ and 940 nm. Nitrogen-Tester displays one value after 30 measurements. The Nitrogen-Tester readings were recorded from the fully expanded uppermost leaf of 30 randomly selected plants per plot (Fig. 1).

\section{Near-infrared camera}

Near infrared images can play a vital role in analysis of plant vegetation based on their capacity of photosynthesis and chlorophyll content on the basis of leaf greenness.

The NIR camera (Make: Public lab community, USA) is low cost and rapid for imaging. This device uses to capture nearinfrared and blue light in the image, but in different colour channels. Vegetation appears pastel blue colour in the image.

The Infrared Point and Shoot is a handheld, battery powered mini camera for doing plant analysis (Fig. 2). It has been modified at the factory to replace its red filter by infrared blocking filter with, effectively exchanging its blue light channel for infrared light. The camera are visible/NIR (457.2-921.7 nm) light sensitive. The field of view $\left(90^{\circ}\right)$ setting allows to either capture the complete area of the image sensor or a smaller area without noticeable loss in quality.

\section{Image aquision using NIR camera mounted on UAV}

An airborne near infrared imaging camera was used to acquire images of 0.54 ha maize experimental field (Fig. 3). A parrot AR. Drone 2.0 was used as the platform for image acquisition. The IR camera was mounted on a frame along with lapse time of 3 seconds of image capturing. The field of view of IR camera was $90^{\circ}$ and exposure time of $1 / 2450$ seconds. No stabilizer or inertial measurement device was used to dampen or measure platform variations, but care was taken to minimize the effects of winds and changes in the drone speed and flight direction. For the given number of bands to be captured and the fields to be imaged, a flight height of 50-60 m (165-198 ft) above ground level and a flight speed of $18 \mathrm{~km} / \mathrm{h}$ were predetermined.

The drone was stabilized at the predetermined flight altitude, speed, and direction before the start of image acquisition and was maintained at the same altitude, speed, and direction during the course of image acquisition.

The NIR images were acquired under sunny and calm conditions from the maize fields on $17^{\text {th }}$ September and $10^{\text {th }}$ October, 2015 after the crop achieved its maximum canopy cover. The ground pixel size achieved was $1.6 \mathrm{~m}$. The geometrically restored NIR images for the maize fields were rectified based on their respective photographic images that were taken in the growing season and georeferenced with the field plot. 


\section{Calibration of NIR camera using greenseeker}

NIR camera works on the principle of light reflected from the target. This camera does not have automatic corrections caused by ambient temperature, light conditions, viewing distance, relative humidity, atmospheric transmission, white balance, external optics and orientation of camera. It can cause inaccuracies in camera image output. Spectra of soil are also mixed in the image captured by the NIR camera and this also affects NDVI extracted from NIR image. So, there is a need to calibrate NIR camera image with any spectra of ground sensing device. Hence hand held Greenseeker was used for the calibration of NIR camera. After getting 3 band (blue, green and red) images of 36 plots by NIR camera, its NDVI was obtained after image analysis by using ENVI 5.1 image processing software considering blue band as NIR band. NIR camera was calibrated by the Greenseeker. Actual NDVI obtained by NIR camera was correlated with the NDVI values obtained from Greenseeker (Fig. 4). Following equation was established for NIR camera:

$y=6.4163 x-0.181$

Where,

$y=$ Calibrated value of NDVI

$\mathrm{x}=$ NDVI of image given by ENVI 5.1 software

Collection of yield data by using yield monitor

Optical sensor type yield monitoring system was installed on indigenous combine harvester (Make: Preet 987) having $4.0 \mathrm{~m}$ cutter bar width. Combine harvester fitted with yield monitor was used to generate yield maps of the maize crop. The system was based upon volumetric flow measurement. The yield monitor was developed by using different sensors and component like optical sensor, GPS, field computer and junction box. The wet basis yield, moisture, speed of combine and area harvested was displayed on the field computer mounted in the cabin of combine harvester.

\section{Error calculation in yield monitor data}

Six plots each of having area $900 \mathrm{~m}^{2}$ were harvested by the combine harvester fitted with yield monitor. The yield data recorded by yield monitor and actual yield was measured by weighing the grains of that harvested area by weighing balance (Table 2). The total yield of the whole field recorded by yield monitor was $3913.90 \mathrm{~kg} / \mathrm{ha}$ while the actual yield was $4138.89 \mathrm{~kg} / \mathrm{ha}$ and the total error calculated was $5.44 \%$ ranging from 4.83 to $5.98 \%$.

\section{Statistical analysis}

Relations were developed for NDVI (NIR camera) and $\mathrm{N}$-tester readings and with yield monitor data by using statistical regression models. Statistical regression models are the most commonly used method for crop yield prediction based on remotely sensed data. Regression modelling was done to develop relationship between a single variable i.e. yield called dependent variable and one independent variable (sensor). The RMSE calculated serves to aggregate the magnitudes of the errors in predictions. Statistical significance was checked by F-test of overall fit, at $\mathrm{P}=0.05$ and 0.01 level of significance.

\section{Results and Discussion}

\section{Spatial and temporal variations for maize} crop

Spatial and temporal data of maize crop recorded by NIR camera and N-Tester. NDVI derived from NIR camera images and $\mathrm{N}$-tester 
values measured at three different stages of maize crop are presented in figures 5 and 6 . Sensor values showed an increasing trend during initial growth stages followed by decline toward the maturity of the crop in all plots. It is observed from the data that values derived from sensors increased initially from crop growth stage V8 (35 DAP) to R1 (55 DAP) and then decreased at stage R4 (78 DAP). This might be due to the fact that growth rate is slow at the beginning of the vegetative period, but increases when new leaves appear. It reaches the maximum canopy coverage in the early reproductive period. NDVI and $\mathrm{N}$-tester values followed the same trend, where the peak sensor values often observed during the silking period (stage R1). Temporal changes on NDVI were mainly due to variation in photosynthetic activity of plant.

NDVI values derived from NIR images were ranging from $0.58-0.80$ and $0.37-0.76$ at growth stages $\mathrm{R} 1$ and $\mathrm{R} 4$ respectively. The value of $\mathrm{N}$-tester recorded at three stages $\mathrm{V} 8$, $\mathrm{R} 1$ and R4 were having range 321- 606, 477680 and 410- 648 respectively. It is also clear from the Fig. 5 and 6, that for plot 19, NDVI and $\mathrm{N}$-Tester values are maximum at all growth stages of the crop and for the plot 31, sensor values were minimum for all growth stages of the crop.

\section{Variation in yield data recorded by yield monitor}

Harvesting was done on $6^{\text {th }}$ November i.e. 103 DAP. Yield map generated by yield monitor during harvesting of maize crop at location $30^{\circ} 54^{\prime} 36.544^{\prime \prime} \mathrm{N}$ latitude and $75^{\circ} 49^{\prime} 03.974^{\prime \prime} \mathrm{E}$ longitude having total area of 0.54 ha is mentioned in Figure 7. The yield measured for the field was divided in six sub-groups i.e. 0-1000 (red), 1000-2000 (maroon), 20003000 (dark yellow), 3000-4000 (light yellow), 4000-5000 (green) and >5000 kg/ha (blue).
Yield map provides the information about the yield variability in every $4 \times 1 \mathrm{~m}^{2}$ grid size (Fig. 7). Each plot of the field was divided in $150 \mathrm{~m}^{2}(15 \times 10 \mathrm{~m})$. The average yield of the whole field recorded by yield monitor was $3913.9 \mathrm{~kg} / \mathrm{ha}$ with standard deviation of $390.12 \mathrm{~kg} / \mathrm{ha}$ and coefficient of variation 9.33 $\%$. Among all the plots minimum yield of maize crop recorded by yield monitor was $3207.6 \mathrm{~kg} / \mathrm{ha}$ in plot 31 with minimum sensor values and maximum yield was $4525.74 \mathrm{~kg} / \mathrm{ha}$ in plot 19 with maximum sensor values as discussed in section 4.1. The total coverage area recorded by GPS was 0.57 hectare but in actual the field was of 0.54 hectare, this variation in area may be due to overlapping of the adjacent rows of the maize crop.

The most prominent growth stage for yield prediction was silking stage (R1). Hence, spatial maps were generated for different sensor values at growth stage R1 (55 DAP) as shown in Figure 8. It's very clear from the spatial maps generated that the manner in which yield of the maize crop was varying, sensor values were also behaving in the same manner as indicated by the different colour shadings of maps. Spatial maps shown that sensor values for plot no. 13 and 19 were maximum and yield for these plots was also maximum as shown by the yield map. Similarly sensor values for plot no. 31 and 36 were minimum and yield for these plots were also minimum as shown by the yield maps.

\section{Relationship between $\mathrm{N}$-Tester value and yield data at various growth stages}

Simple linear regression models to develop empirical relationship between $\mathrm{N}$-Tester value and yield data for three growth stages of maize crop are shown in Figure 9.

The values of coefficient of determination $\left(\mathrm{R}^{2}\right)$ for yield prediction equations for $\mathrm{N}$ Tester were $0.79,0.84$ and 0.83 with 
corresponding values of RMSE 174.85, 152.88 and $160.20 \mathrm{~kg} / \mathrm{ha}$ at grand growth (V8), silking (R1) and dough stage (R4) respectively. Statistical significance of the developed empirical relationship was also checked by F-test of overall fit. It was found that at $\mathrm{P}=0.01$ level of significance, there was significant effect of $\mathrm{N}$-Tester value on yield data at all growth stages of maize. It means that increase or decrease in N-Tester value during the maize growth period is related to the maize yield.

Fig.1 Measurement of leaf greenness using N-Tester
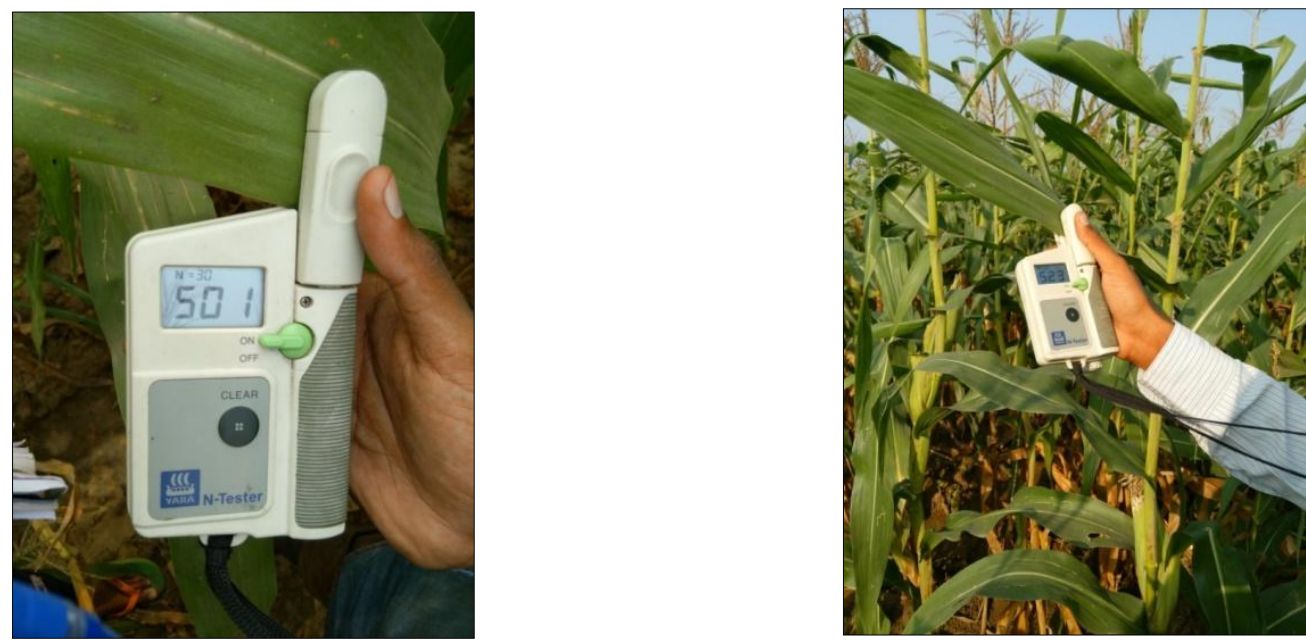

Fig.2 Various components and modes of NIR camera
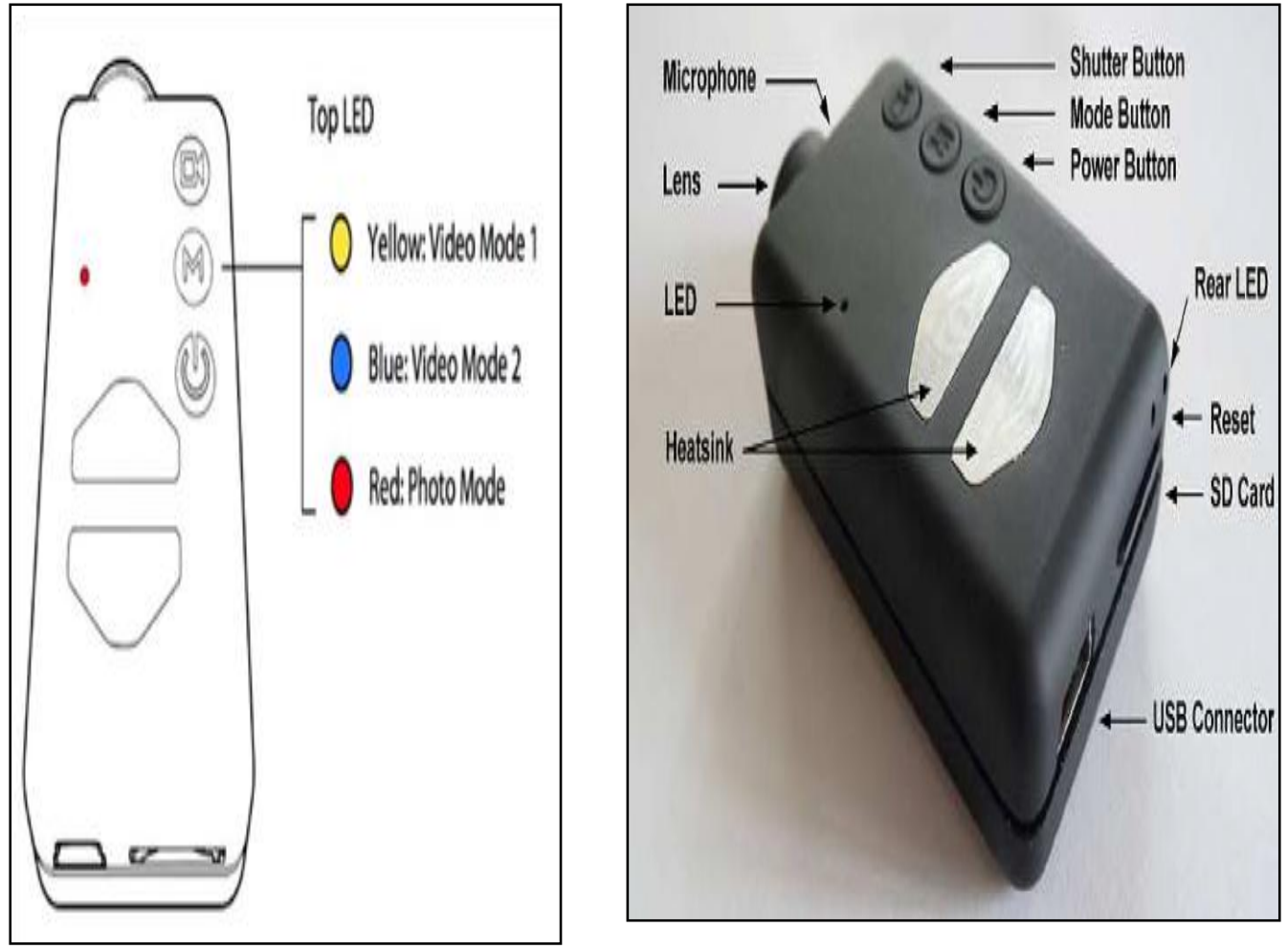
Fig.3 Aerial image capturing by NIR camera mounted on UAV at different crop growth stages

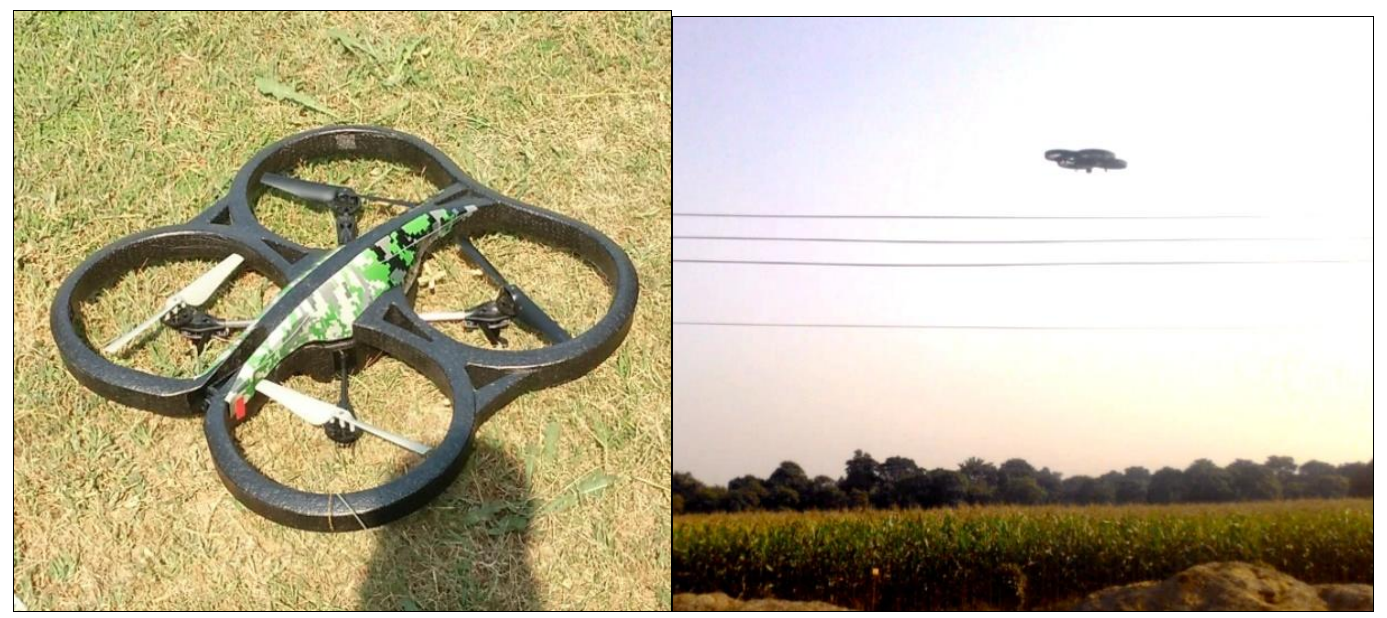

Fig.4 Relationship between NDVI values measured by NIR camera and Greenseeker

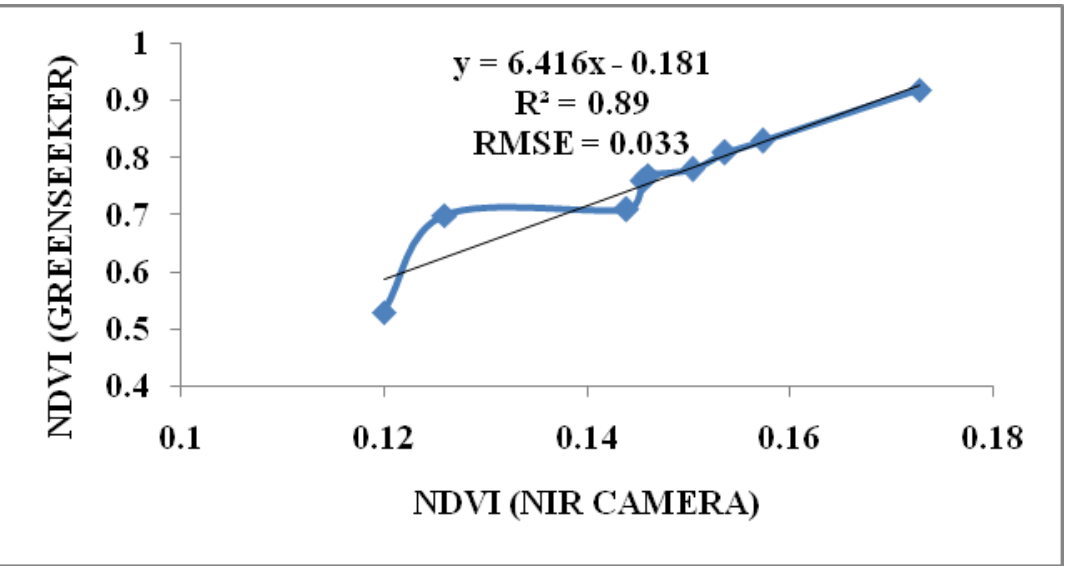

Fig.5 Temporal and spatial changes on N-Tester for maize crop

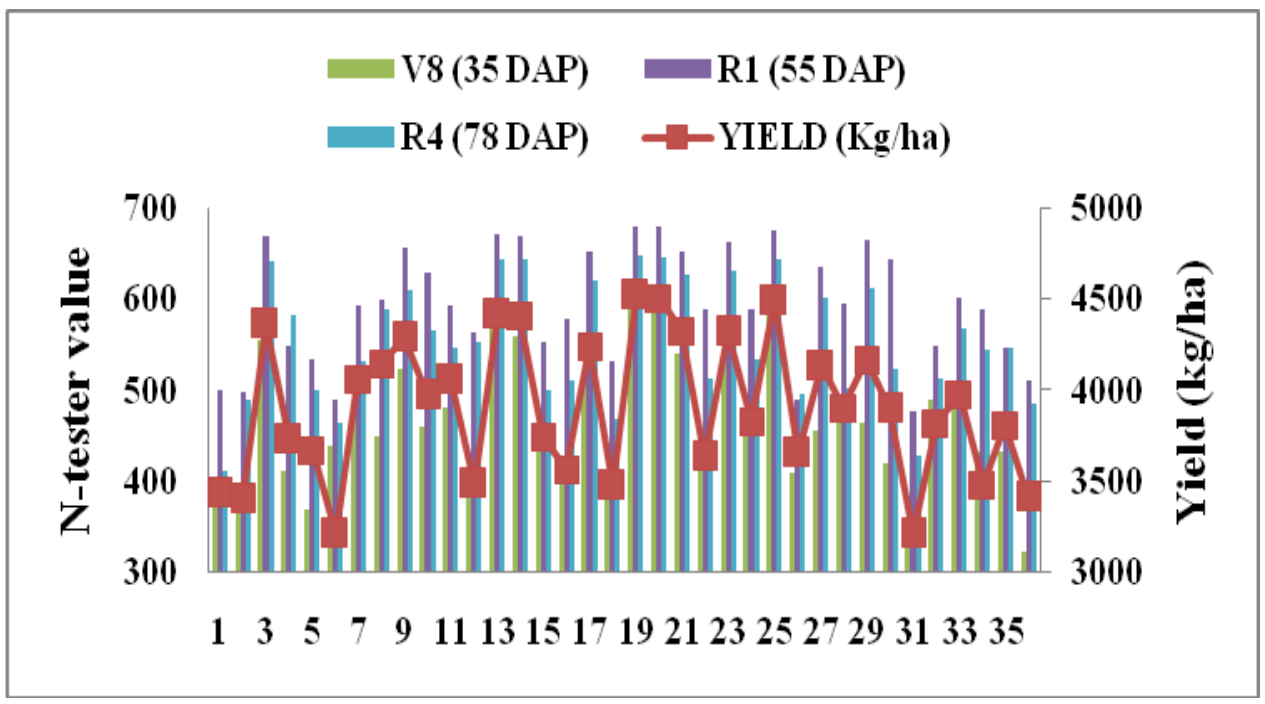


Fig.6 Temporal and spatial changes on NDVI (NIR camera) for maize crop

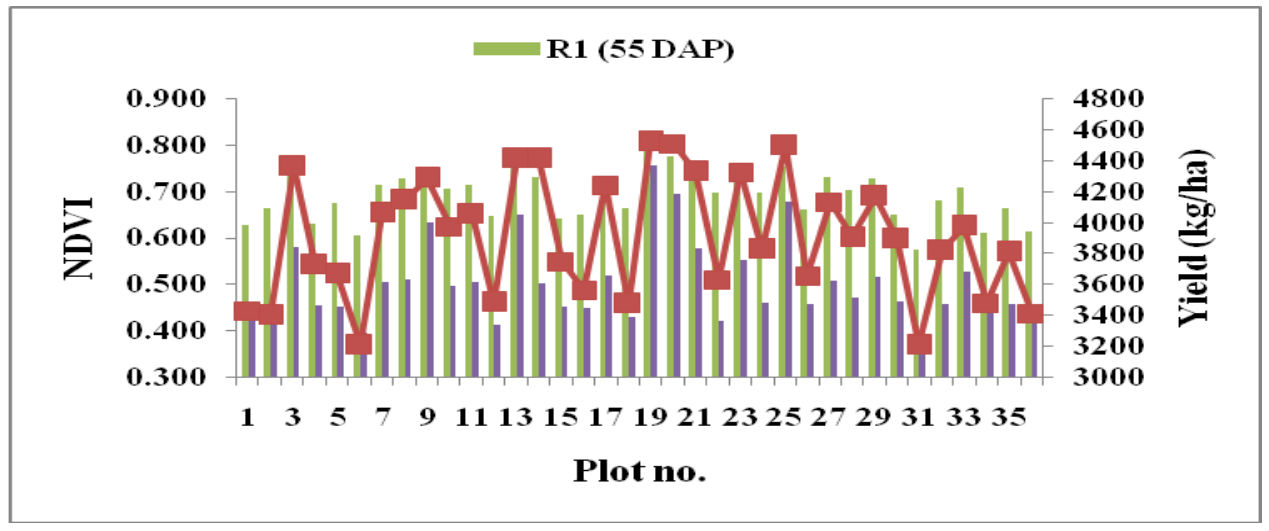

Fig.7 Yield map generated by yield monitor during harvesting of maize crop
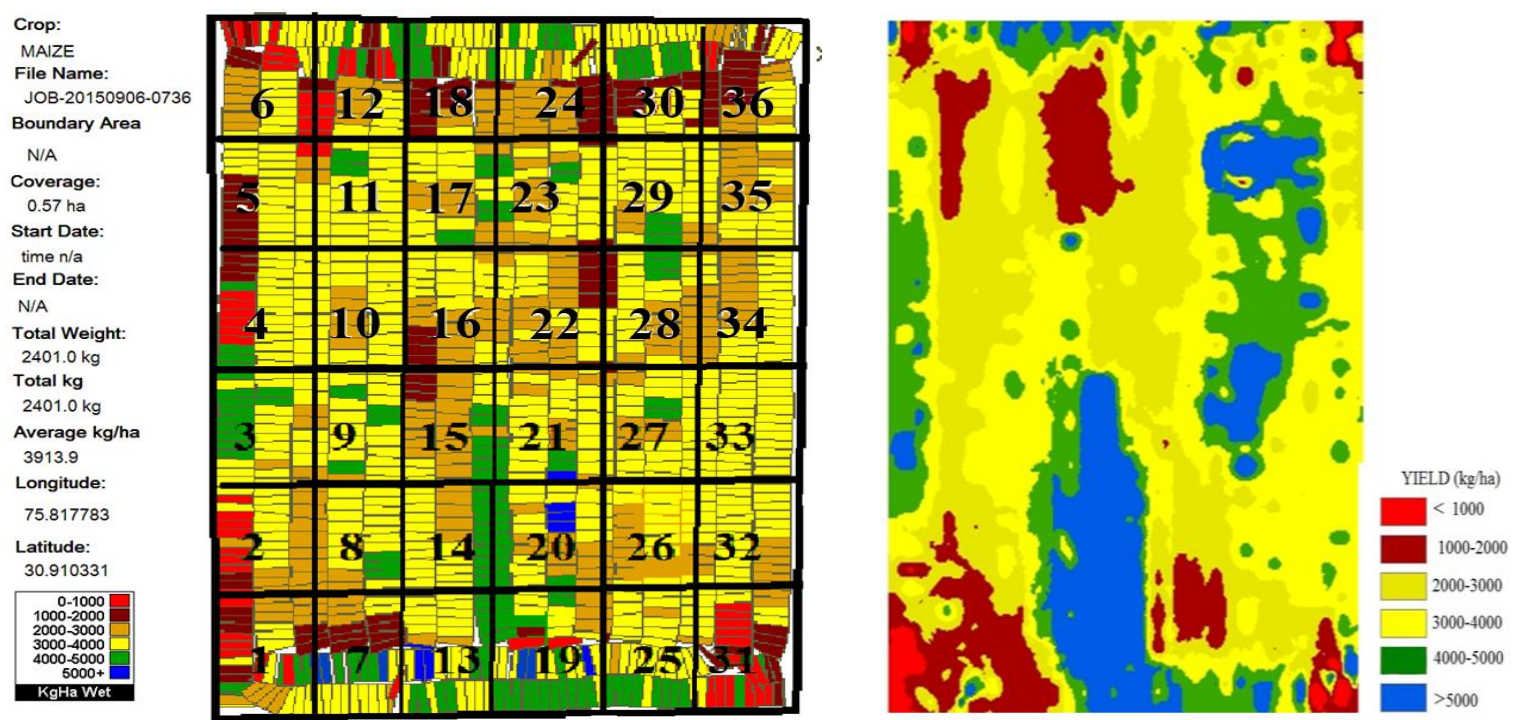

Fig.8 Spatial maps generated for N-Tester and NDVI values at R1 (55 DAP)

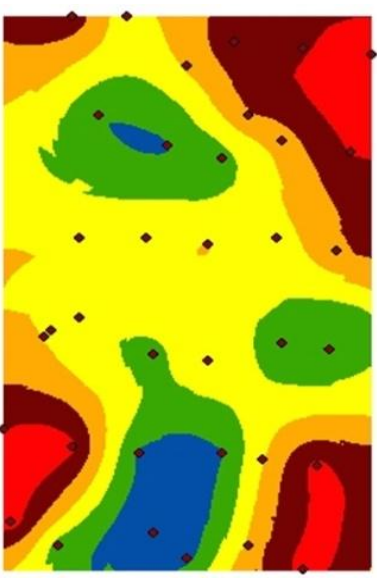

a) $\mathrm{N}$-Tester

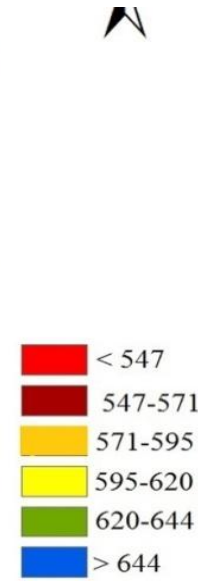

$547-57$ 571-595 644
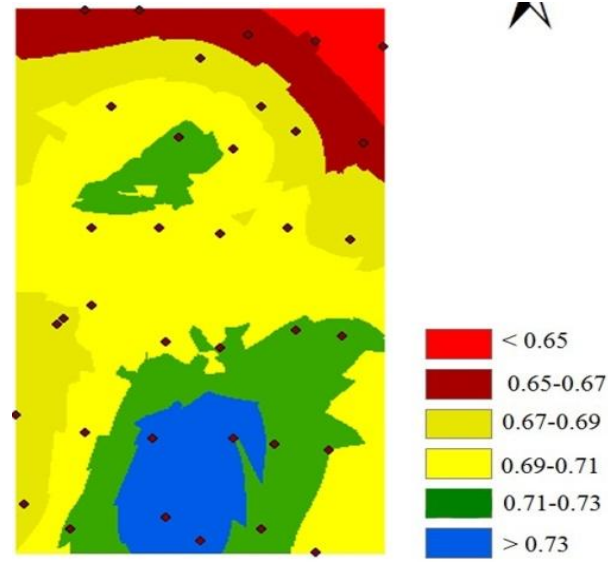

b) NDVI (NIR Camera) 
Fig.9 Relationship between N-Tester value and yield at V8, R1and R4
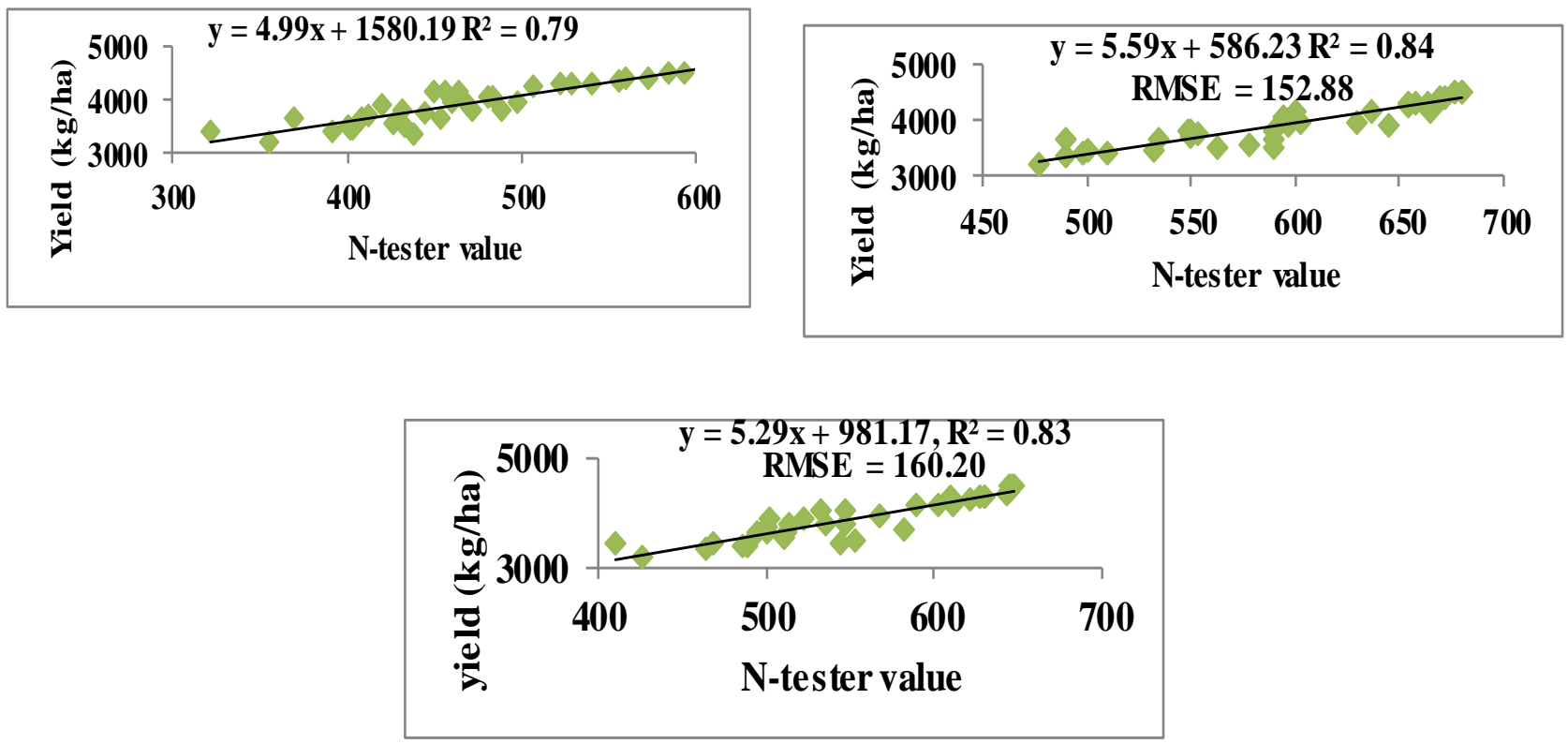

Fig.10 Relationship between NDVI and yield at R1 stage (55 DAP)

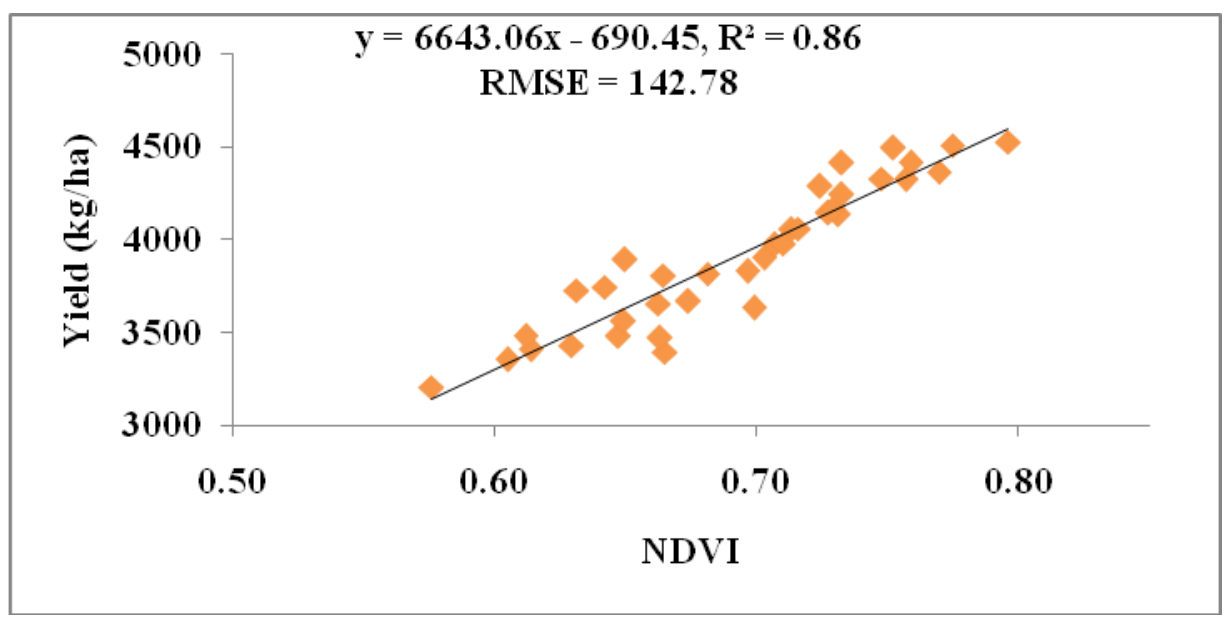

Fig.11 Relationship between NDVI and yield at R4 stage (78 DAP)

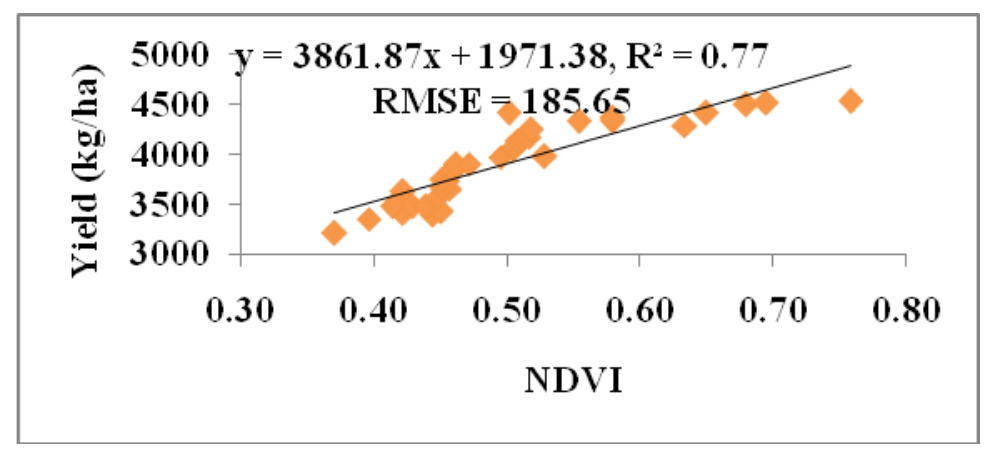


Table.1 Dates of measurements of N-Tester value and image acquisition

\begin{tabular}{|c|c|c|}
\hline Growth stages & Days after planting (DAP) & Date \\
\hline Grand growth stage (V8) & 35 & August 28, 2015 \\
\hline Silking stage (R1) & 55 & September 17, 2014 \\
\hline Dough stage (R4) & 78 & October 10, 2014 \\
\hline
\end{tabular}

Table.2 Yield data with error in yield measurement

\begin{tabular}{|c|c|c|c|}
\hline Parameters & Yield by yield monitor(kg/ha) & Actual yield(kg/ha) & \% Error \\
\hline 1 & 3656.59 & 3855.56 & 5.16 \\
\hline 2 & 4001.20 & 4255.56 & 5.98 \\
\hline 3 & 3975.23 & 4211.11 & 5.60 \\
\hline 4 & 4191.43 & 4455.56 & 5.93 \\
\hline 5 & 4042.41 & 4255.56 & 5.01 \\
\hline 6 & 3616.54 & 3800.00 & 4.83 \\
\hline Total & $\mathbf{3 9 1 3 . 9 0}$ & $\mathbf{4 1 3 8 . 8 9}$ & $\mathbf{5 . 4 4}$ \\
\hline
\end{tabular}

Table.3 Values of coefficient of determination $\left(\mathrm{R}^{2}\right)$ and RMSE at different growth stages of maize crop

\begin{tabular}{|c|c|c|c|c|}
\hline \multirow{2}{*}{ Stages } & \multicolumn{2}{|c|}{ N-Tester } & \multicolumn{2}{c|}{ NDVI(NIR Camera) } \\
\cline { 2 - 5 } & $\mathbf{R}^{\mathbf{2}}$ & RMSE & $\mathbf{R}^{\mathbf{2}}$ & RMSE \\
\hline V8(35 DAP) & 0.79 & 174.85 & - & - \\
\hline R1(55 DAP) & 0.84 & 152.88 & 0.86 & 142.78 \\
\hline R4(78 DAP) & 0.83 & 160.20 & 0.77 & 185.65 \\
\hline
\end{tabular}

It is also clear from the figures that maximum $\mathrm{R}^{2}(0.84)$ and minimum RMSE (152.88 kg/ha) value of maize yield for $\mathrm{N}$-Tester value was observed in silking stage (R1). At grand growth stage (V8) the plant nitrogen is utilized for the canopy development, hence NTester value was lesser at this stage.

\section{Relationship between NDVI (NIR Camera) and yield data at various growth stages}

Simple linear regression models to developed empirical relationship between NDVI and yield data for two growth stages of maize crop are shown in Figures 10 and 11. The values of coefficient of determination $\left(\mathrm{R}^{2}\right)$ for yield prediction equations for NDVI were 0.86 and 0.77 with corresponding values of RMSE 142.78 and $185.65 \mathrm{~kg} / \mathrm{ha}$ at silking
(R1) and dough stage (R4) respectively. Statistical significance of the developed empirical relationship was also checked by Ftest of overall fit. It was found that at $\mathrm{P}=0.01$ level of significance, there was significant effect of NDVI on yield data at all growth stages of maize. It means that increase or decrease in NDVI during the maize growth period is related to the maize yield.

It is also clear from the figures that maximum $\mathrm{R}^{2}(0.86)$ and minimum RMSE (142.78 kg/ha) value of maize yield for NDVI was observed in silking stage (R1). At dough stage (R4) spectral reflection decreases at NIR band due to deficiency of chlorophyll in leaves. In dough stage of maize the coefficient of determination is lower due increase in reflectance of the maize canopy was also 
caused by dark yellow colour tassels, which was most pronounced in the red reflectance region and decreased the sensitivity of NDVI to variation in yield.

The coefficient of determination $\left(R^{2}\right)$ and RMSE values for the relationships developed between sensor values and yield data at different growth stages of maize crop are summarized in the Table 4. The best correlation was obtained between NDVI and yield with coefficient of determination 0.86 and RMSE $142.78 \mathrm{~kg} / \mathrm{ha}$ at silking growth stage (R1).

NDVI and $\mathrm{N}$-tester value increased initially from crop growth stage V8 (35 DAP) to R1 (55 DAP) and then decreased at stage R4 (78 DAP), the peak sensor values were observed during the silking period (stage R1). NDVI values derived from NIR images were ranging from $0.58-0.8$ and $0.37-0.76$ at growth stages $\mathrm{R} 1$ and $\mathrm{R} 4$ respectively. The values of $\mathrm{N}$ tester recorded at three stages $\mathrm{V} 8, \mathrm{R} 1$ and $\mathrm{R} 4$ were having range 321-606, 477- 680 and 410- 648 respectively. The average yield of the field recorded by yield monitor was $3913.9 \mathrm{~kg} / \mathrm{ha}$ with standard deviation of $390.12 \mathrm{~kg} / \mathrm{ha}$ and coefficient of variation of $9.33 \%$. The data revealed that the grid size has non-significant effect on yield and error in yield at $5 \%$ level of significance. Spatial maps of NDVI and N-tester values at most prominent crop growth stage i.e. R1 generated showed that the manner in which yield of the maize crop was varying, sensor values were also behaving in the same manner as indicated by the different colour shadings of maps. The values of coefficient of determination $\left(R^{2}\right)$ for yield prediction equations for $\mathrm{N}$-Tester were $0.79,0.84$ and 0.83 with corresponding values of RMSE $174.85,152.88$ and $160.20 \mathrm{~kg} / \mathrm{ha}$ at grand growth (V8), silking (R1) and dough stage (R4) respectively. The values of coefficient of determination $\left(\mathrm{R}^{2}\right)$ for yield prediction equations for NDVI were 0.86 and
0.77 with corresponding values of RMSE 142.78 and $185.65 \mathrm{~kg} / \mathrm{ha}$ at silking (R1) and dough stage (R4) respectively. NDVI and Ntester values were positively correlated with yield data at all growth stages of maize. It was concluded that increase or decrease in sensor values during the maize growth period were related to the maize yield. It was concluded that the silking stage (R1 stage) i.e. 55 DAP was the most prominent stage for yield prediction using NDVI. Yield can be predicted 48 days before harvesting using reflectance data captured by NIR camera and $\mathrm{N}$-Tester.

\section{References}

Anand, M. H., and Byju, G. 2008. Chlorophyll meter and leaf colour chartto estimate chlorophyll content, leaf colour and yield of cassava. Photosynthetica, 46: 511-16.

Bala, S. K., and Islam, A. S. 2009. Correlation between potato yield and MODIS-derived vegetation indices. Int. J. Rem. Sens., 30: 2491-07.

Diker, K., and Bausch, W. C. 2003. Potential use of nitrogen reflectance index to estimate plant variables and yield of corn. Biosyst. Eng., 85: 437-47.

Diker, K., Bausch, W. C. and Heermann, D. F. 2001. Monitoring temporal changes of irrigated corn by aerial images. ASAE, 44: 984-91.

Halloran, K., 2004. Analysing the relationship between high resolution digital multispectral imagery and yield data. Honours Dissertation, Curtin University of Technology, Perth.

Jensen, T., Apan, A., Young, F. and Zeller, L. 2007. Detecting the attributes of a wheat crop using digital imagery acquired from a low-altitude platform. Comp. Elect. Agric., 59: 66-77.

Reyniers, M., Vrindts, E. and Baerdemaeker, J. D. 2006. Comparison of an aerial- 
based system and on the ground continuous measuring device to predict yield of winter wheat. Europ. J. Agron., 24: 87-94.

Rostami, M., Koocheki, A. H. R., Mahallati, M. N. and Kofi, M. 2008. Evaluation of chlorophyll meter (spad) data for prediction of nitrogen status in corn (Zea mays L.). Am. Eur. J. Agric. Environ. Sci., 3: 79-85.

Schepers, J. S., Francis, D. D. and Power, J. F. 1998. Tissue analysis to improve nitrogen management practices. In Proc Clean Water-Clean Environment-21 $1^{\text {st }}$ Century. Vol. II: Nutrients. Kansas City, MO. Am. Soc. Agri. Eng., St. Joseph, MI PP. 195-98.

Schepers, J. S., Francis, D. D., Vigil, M. and Below, F. E. 1992. Comparison of corn leaf nitrogen concentration and chlorophyll meter readings. Comm. Soil. Sci. Plant. Anal., 20: 2173-87.

Shanahan, J. F., Schepers, J. S., Francis, D. D., Varvel, G. E., Wilhelm, W. W., Tringe, J. M., Schlemmer, M. R. and Major, D. J. 2001. Use of remotesensing imagery to estimate corn grain yield. Agron. J., 93:583-89.

Sharma, K., Singh, M., Singh, B., Sharma, A. and Mishra, P. K. 2012. Development and evaluation of grain yield monitoring system. J. Agric. Eng., 49: 81-84.

Singh, M., Sharma, A. and Singh, B. 2012. Investigation into yield monitoring sensor installed on indigenous grain combine harvester. $6^{\text {th }}$ Int. Conf. on Sens. Tech., Kolkata. ICST PP. 46-51.

Taylor, J. C., Wood, G. A. and Thomas, G. 1997. Mapping yield potential with remote sensing. Prec. Agric., 97: 713-20.

Tomer, M. D., Anderson, J. L. and Lamb, J. A. 2005. Assessing corn yield and nitrogen uptake variability with digitized aerial infrared photographs. Am. Soc. Photog. Eng. Rem. Sens., 63:299-06.

Villegas, V. H., and Fritschi, F. B. 2013. Relationships among vegetation indices derived from aerial photographs and soybean growth and yield. Crop. Sci., 53: 2631-42.

Yang, C., and Anderson, L. G. 1996. Determining within field management zones for grain sorghum using aerial videography. Proc. 26th Int. Symp. on Rem. Sens. of Environ., PP. 606-11.

Yang, C., Everitt, J. H. and Bradford, J. M.2004. Airborne hyperspectral imagery and yield monitor data for mapping cotton yield variability. Prec. Agric., 5: 445-61.

Zand, F., and Matinfar, H. R.2012. Winter wheat yield estimation base upon spectral data and ground measurement. Annals. Bio. Research, 3: 5169-77.

Zhang, M., Hendley, P. and Drost, D. 1998. Corn and soybean yield indicators using remotely sensed vegetation index. Proc. $4^{\text {th }}$ Conf. on Prec. Agric., PP. 1475-81.

\section{How to cite this article:}

Sanodiya, R., M. Singh, V. Bector, B. Patel and Pramod Mishra. 2017. Yield Prediction by Integrating NDVI and N-Tester Data with Yield Monitor Data. Int.J.Curr.Microbiol.App.Sci. 6(10): 1296-1307. doi: https://doi.org/10.20546/ijcmas.2017.610.153 